\title{
THRESHOLD OF RESPONSE OF THE CEREBRAL VESSELS OF MAN TO INCREASE IN BLOOD CARBON DIOXIDE ${ }^{1}$
}

\author{
By JOHN L. PATTERSON, JR.,2 ALBERT HEYMAN, ${ }^{3}$ LOUIS L. BATTEY, 4 AND \\ ROBERT W. FERGUSON 2

\begin{abstract}
(From the Departments of Physiology and Medicine, Emory University School of Medicine, the Medical Service of Grady Memorial Hospital, Atlanta, Ga., and the Department of Medicine, Medical College of Virginia, Richmond, Va.)
\end{abstract}

(Submitted for publication December 29, 1953; accepted August 17, 1955)

The level of carbon dioxide in the blood is now generally accepted as one of the major factors in the regulation of the cerebral circulation. It was first shown in experimental animals that increase in blood carbon dioxide exerts a vasodilator effect on cerebral blood vessels $(1,2)$. Similar effects were postulated in man by Lennox and Gibbs (3) on the basis of decrease in the cerebral arteriovenous oxygen difference. Conclusive evidence of the effects of carbon dioxide on cerebral blood flow in man was provided by the experiments of Kety and Schmidt with the nitrous oxide method. Reduction in arterial $\mathrm{CO}_{2}$ through hyperventilation was shown to produce a decrease in blood flow, (4) whereas increase in arterial $\mathrm{CO}_{2}$ through inhalation of 5 per cent and 7 per cent carbon dioxide was found to cause a striking increase in blood flow (5).

The above observations on man, which were concerned with large-scale effects, do not in themselves permit a precise formulation of the role of carbon dioxide in the control of the cerebral circulation. The minimal changes in blood $\mathrm{CO}_{2}$ which will evoke vascular responses must be known, together with the degrees of response which are produced by given increments of change in $\mathrm{CO}_{2}$ beyond these threshold values. Knowledge of the minimal increase in arterial $\mathrm{CO}_{2}$ required to dilate cerebral vessels has potential therapeutic application in the treatment of certain states of severe impairment of blood flow to the brain. Carbon dioxide in $\mathbf{5}$ per cent or greater concentra-

\footnotetext{
1 Supported in part by Contracts N9onr92500 and Nonr-1134(01), Office of Naval Research, and in part by a grant from the National Institutes of Health, U. S. Public Health Service.

2 Present address: Department of Medicine, Medical College of Virginia, Richmond, Va.

${ }^{3}$ Present address: Department of Neurology, Duke University School of Medicine, Durham, N. C.

4 Present address : 1407 Gwinnett Street, Augusta, Ga.
}

tion has the disadvantages of raising blood pressure $(5,6)$ and producing uncomfortable dyspnea within a relatively few minutes (7). It appeared possible, however, that some lower concentration of carbon dioxide might prove more tolerable, while still retaining vasodilator properties.

The present studies were concerned with the threshold of response of the cerebral vessels of man to increase in blood carbon dioxide. Cerebral blood flow determinations were made with the nitrous oxide method, employing concentrations of 2.5 and 3.5 per cent $\mathrm{CO}_{2}$ in the inspired gas, and the associated changes in blood gases and $\mathrm{pH}$ were measured.

\section{METHODS}

The subjects for these studies were hospital patients convalescing from a variety of illnesses in which the brain was not involved. Seven patients and five normal volunteer subjects were given 2.5 per cent carbon dioxide by inhalation and 12 patients and seven normal subjects were given 3.5 per cent carbon dioxide. The mean ages of these two groups were 30 and 34 years, respectively. Cerebral blood flow (CBF) before and during carbon dioxide inhalations was determined by the nitrous oxide method (8) with slight modifications (9). Six of the 28 subjects were studied by measurements of cerebral arteriovenous gas differences alone and one subject (H. J.) separately by both techniques. Cerebral oxygen consumption ( $\mathrm{CMR}_{\mathrm{O}_{2}}$ ) was determined from the cerebral blood flow multiplied by the cerebral arteriovenous oxygen difference, $(A-V)_{02}$. The values for $(\mathrm{A}-\mathrm{V})_{\mathrm{O}_{2}}$ were obtained from analyses of arterial and internal jugular blood samples drawn just before and just after the cerebral blood flow procedure and pooled. The cerebral vascular resistance (CVR) was calculated by dividing the blood flow into the mean arterial pressure, measured several times during the CBF procedure from either the femoral or brachial arteries with a damped mercury manometer.

Control observations of the cerebral circulation were made with the standard gas mixture for the nitrous oxide method (15 per cent $\mathrm{N}_{2} \mathrm{O}, 21$ per cent $\mathrm{O}_{2}, 64$ per cent $\mathrm{N}_{2}$ ). Following this the patient was given a mixture contain- 


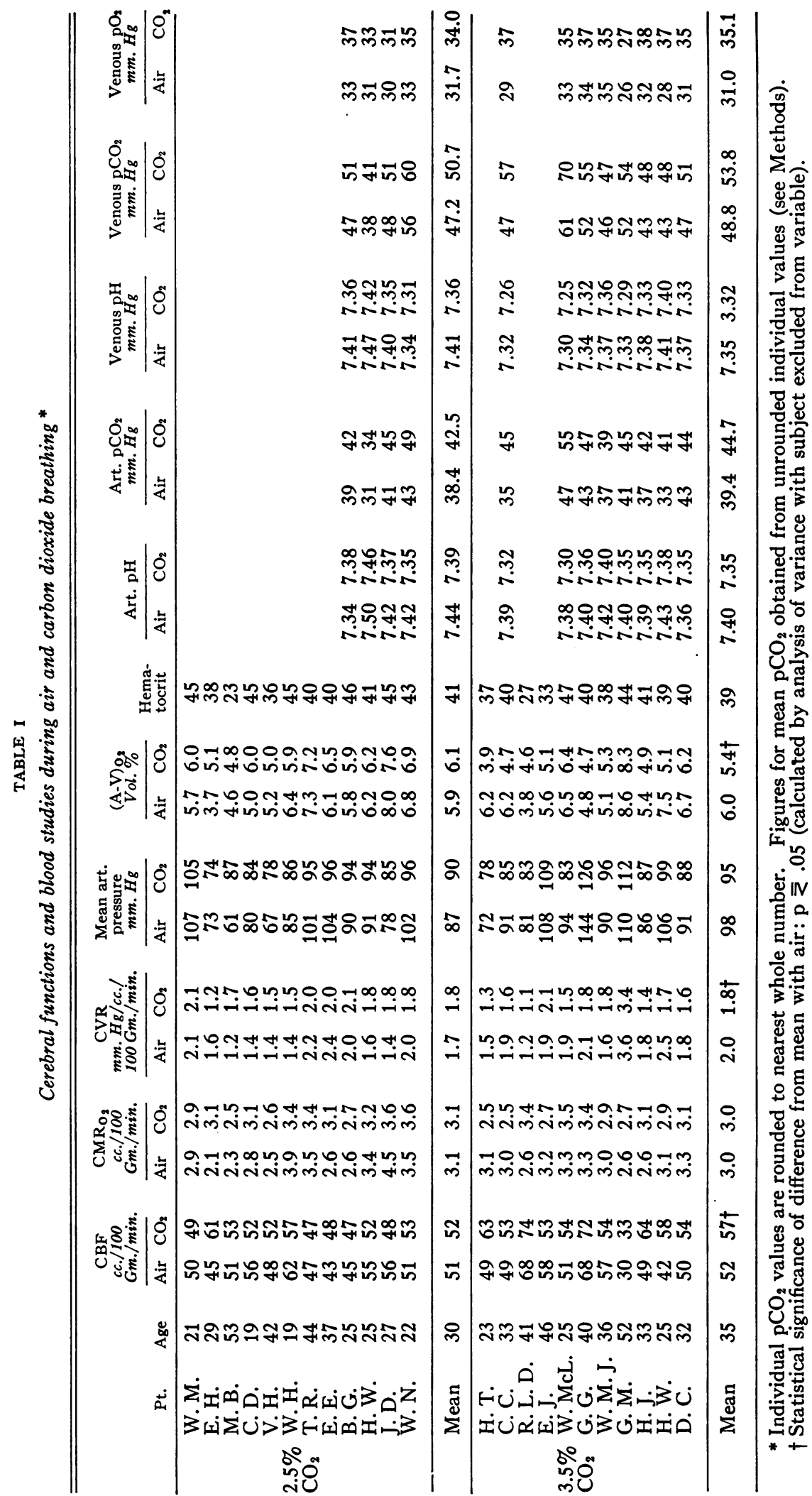


ing 2.5 per cent or 3.5 per cent $\mathrm{CO}_{2}$, with 21 per cent $\mathrm{O}_{2}$ and the remainder $\mathrm{N}_{2}$. At the end of 15 to 20 minutes this mixture was changed to gas containing the same percentage of $\mathrm{CO}_{2}$ and $\mathrm{O}_{2}$, together with 15 per cent $\mathrm{N}_{2} \mathrm{O}$, and the experimental blood flow determination carried out.

The pooled blood samples of arterial and venous blood were analyzed for oxygen and carbon dioxide content by the combined procedure for both gases described by Peters and Van Slyke (10), as modified for the presence of nitrous oxide by Kety and Schmidt (8). Oxygen capacity of the blood samples was determined by the method of Roughton, Darling, and Root (11). Blood $\mathrm{pH}$ was measured with a Cambridge Model R. pH meter, with appropriate corrections to body temperature (12). Carbon dioxide tensions $\left(\mathrm{pCO}_{2}\right)$ were obtained from the $\mathrm{pH}, \mathrm{CO}_{2}$ content and hematocrit by means of the nomogram of Singer and Hastings (13). The individual $\mathrm{pCO}_{2}$ values were estimated to the nearest 0.1 $\mathrm{mm}$. Hg from an enlarged print of this nomogram. This was done to define as precisely as possible the blood flow $-\mathrm{pCO}_{2}$ relations over a narrow range of $\mathrm{CO}_{2}$ increase. No implication is intended, however, that the method possesses such accuracy in terms of the absolute magnitude of individual determinations. Venous oxygen tension was determined from the $\mathrm{pH}$ and the per cent of oxygen saturation, using the oxygen-hemoglobin dissociation curves of Dill (14). Observations were made on the character of the subject's breathing, but respiratory minute volumes were not measured.

\section{RESULTS}

Inhalation of 2.5 per cent carbon dioxide produced very little change in the mean values of the cerebral blood flow, cerebral oxygen consumption or vascular resistance (Table I). The mean arterial $\mathrm{pH}$ and $\mathrm{pCO}_{2}$ values with air and $\mathrm{CO}_{2}$ breathing were respectively: 7.44 and $7.39,38.4$ and $42.5 \mathrm{~mm}$. $\mathrm{Hg}$. A comparable group of seven subjects given 2.5 per cent $\mathrm{CO}_{2}$ for 15 minutes showed a decrease in the mean value for arterial $\mathrm{pH}$ from 7.37 to 7.34 and an increase in arterial $\mathrm{pCO}_{2}$ from 41.3 to $45.6 \mathrm{~mm}$. $\mathrm{Hg}$. Dyspnea and increase in rate or depth of the subjects' breathing were either slight or not detectable. The same concentration of carbon dioxide was also well tolerated by 10 patients with cerebral vascular accidents (7) for periods of 30 minutes to one hour.

Inhalation of carbon dioxide in 3.5 per cent concentration was associated with a mean increase of 10 per cent $(p<.05)$ in cerebral blood flow and a comparable decrease in cerebral vascular resistance $(\mathrm{p}<.05)$. There was no change in cerebral oxygen consumption. There was, however, a decrease in the cerebral arteriovenous oxygen difference.
The mean values of $(\mathrm{A}-\mathrm{V})_{02}$ for air and $\mathrm{CO}_{2}$ breathing in the patients studied by the nitrous oxide method were 6.0 and 5.4 volumes per cent $(\mathrm{p}=.05)$, respectively. In the larger group comprising 16 observations on 15 subjects, the mean value for $(\mathrm{A}-\mathrm{V})_{0_{2}}$ was 6.4 volumes per cent with air and 5.5 volumes per cent with $\mathrm{CO}_{2}$ breathing $(\mathrm{p}<.01)$. In 12 of these observations there was a fall in $(\mathrm{A}-\mathrm{V})_{0_{2}}$ of 0.5 volumes per cent or more during $\mathrm{CO}_{2}$ inhalation, and in four there was little change (Table II). Changes in the blood gas tensions and $\mathrm{pH}$ in the eight patients of the nitrous oxide group in whom these functions were studied were almost identical with those in the larger group of 15 subjects. In these 15 individuals 3.5 per cent carbon dioxide produced the following increases: arterial $\mathrm{pCO}_{2}, 5.3 \mathrm{~mm}$. $\mathrm{Hg}$; jugular venous $\mathrm{pCO}_{2}, 4.3 \mathrm{~mm}$. $\mathrm{Hg}$; jugular venous $\mathrm{pO}_{2}, 4.7$ $\mathrm{mm}$. Hg. Arterial $\mathrm{pH}$ fell .04 unit and jugular venous $\mathrm{pH} .03$ unit with this concentration of carbon dioxide.

The relation between increase in arterial $\mathrm{CO}_{2}$ tension and the corresponding change in two different measures of cerebral blood flow is shown in Figure 1. These measures are the cerebral blood flow as determined by the nitrous oxide method, and the cerebral blood flow as indicated by the reciprocal of the arteriovenous oxygen difference. In order to make them comparable, the values for both determinations during carbon dioxide inhalation are shown as percentage of control. Each of the points as plotted represents the mean obtained with a given concentration of inspired $\mathrm{CO}_{2}$ in those subjects on whom both the $\mathrm{CBF}_{\mathrm{N}_{2} \mathrm{O}}$ and $\frac{1}{(\mathrm{~A}-\mathrm{V})_{\mathrm{O}_{2}}}$ measurements were made. The function $\frac{1}{(\mathrm{~A}-\mathrm{V})_{\mathrm{O}_{2}}}$ represents a valid measure of changes in blood flow where $\mathrm{O}_{2}$ consumption is constant. The data for 5 per cent and 7 per cent $\mathrm{CO}_{2}$ are taken from the work of Kety and Schmidt (5). However, supplementary observations made with 5 per cent $\mathrm{CO}_{2}$ in our laboratory (7) in four patients with cerebral vascular accidents showed a decrease in the cerebral arteriovenous oxygen difference only slightly less than that observed by Kety and Schmidt in normal subjects.

It is evident in Figure 1 that a rather abrupt change in the slope of both curves must occur between the 2.5 per cent and 3.5 per cent inspired 
TABLE II

Arterial and internal jugular blood gas and $p H$ determinations in sixteen observations on fifteen subjects during air and 3.5 per cent carbon dioxide inhalation *

\begin{tabular}{|c|c|c|c|c|c|c|c|c|c|c|c|c|c|c|}
\hline \multirow[b]{2}{*}{ Patient } & \multirow[b]{2}{*}{ Age } & \multicolumn{2}{|c|}{$\begin{array}{c}\text { Art. } \mathrm{pCO}_{2} \\
\mathrm{~mm} . \mathrm{Hg}\end{array}$} & \multicolumn{2}{|c|}{ Art. pH } & \multicolumn{2}{|c|}{$\begin{array}{c}\text { Ven. } \mathrm{pCO}_{2} \\
m m . \mathrm{Hg}\end{array}$} & \multicolumn{2}{|c|}{ Ven. pH } & \multicolumn{2}{|c|}{$\begin{array}{c}\text { Ven. } \mathrm{pO}_{2} \\
m m . H g\end{array}$} & \multicolumn{2}{|c|}{$\begin{array}{l}\text { (A-V)o2 } \\
\text { Vol. \% }\end{array}$} & \multirow{2}{*}{$\begin{array}{l}\frac{1}{\left(\mathrm{~A}-\mathrm{V} \mathrm{O}_{2}\right.} \text { as } \% \\
\frac{\text { of control (air) }}{\mathrm{CO}_{2}}\end{array}$} \\
\hline & & Air & $\mathrm{CO}_{2}$ & Air & $\mathrm{CO}_{2}$ & Air & $\mathrm{CO}_{2}$ & Air & $\mathrm{CO}_{2}$ & Air & $\mathrm{CO}_{2}$ & Air & $\mathrm{CO}_{2}$ & \\
\hline $\begin{array}{l}\text { C. C. } \\
\text { W. McL. } \\
\text { G. G. } \\
\text { W. M. J. } \\
\text { G. M. } \\
\text { C. P. } \\
\text { J. S. } \\
\text { C. H. } \\
\text { E. C. } \\
\text { H. J. } \\
\text { H. W. } \\
\text { D. C. } \\
\text { H. J. } \\
\text { B. G. } \\
\text { C. W. } \\
\text { G. H. }\end{array}$ & $\begin{array}{l}33 \\
25 \\
40 \\
36 \\
52 \\
22 \\
25 \\
58 \\
37 \\
33 \\
25 \\
32 \\
33 \\
27 \\
26 \\
31\end{array}$ & $\begin{array}{l}35 \\
47 \\
43 \\
37 \\
41 \\
40 \\
42 \\
48 \\
37 \\
37 \\
32 \\
43 \\
38 \\
40 \\
41 \\
39\end{array}$ & $\begin{array}{l}45 \\
55 \\
47 \\
39 \\
45 \\
40 \\
49 \\
55 \\
45 \\
42 \\
41 \\
44 \\
44 \\
47 \\
42 \\
44\end{array}$ & $\begin{array}{l}7.39 \\
7.38 \\
7.40 \\
7.42 \\
7.40 \\
7.38 \\
7.39 \\
7.31 \\
7.43 \\
7.39 \\
7.43 \\
7.36 \\
7.40 \\
7.41 \\
7.39 \\
7.42\end{array}$ & $\begin{array}{l}7.32 \\
7.30 \\
7.36 \\
7.40 \\
7.35 \\
7.38 \\
7.38 \\
7.27 \\
7.37 \\
7.35 \\
7.38 \\
7.35 \\
7.35 \\
7.35 \\
7.36 \\
7.37\end{array}$ & $\begin{array}{l}47 \\
61 \\
52 \\
46 \\
52 \\
48 \\
51 \\
58 \\
52 \\
43 \\
42 \\
47 \\
46 \\
48 \\
51 \\
47\end{array}$ & $\begin{array}{l}57 \\
70 \\
55 \\
47 \\
54 \\
49 \\
55 \\
61 \\
57 \\
48 \\
48 \\
51 \\
50 \\
53 \\
53 \\
51\end{array}$ & $\begin{array}{l}7.32 \\
7.30 \\
7.34 \\
7.37 \\
7.33 \\
7.32 \\
7.35 \\
7.28 \\
7.35 \\
7.38 \\
7.41 \\
7.37 \\
7.37 \\
7.38 \\
7.35 \\
7.38\end{array}$ & $\begin{array}{l}7.26 \\
7.25 \\
7.32 \\
7.36 \\
7.29 \\
7.32 \\
7.34 \\
7.24 \\
7.32 \\
7.33 \\
7.36 \\
7.33 \\
7.33 \\
7.34 \\
7.32 \\
7.35\end{array}$ & $\begin{array}{l}29 \\
33 \\
34 \\
35 \\
26 \\
27 \\
35 \\
30 \\
24 \\
32 \\
28 \\
31 \\
38 \\
30 \\
32 \\
31\end{array}$ & $\begin{array}{l}37 \\
35 \\
37 \\
35 \\
27 \\
32 \\
38 \\
41 \\
28 \\
38 \\
37 \\
35 \\
46 \\
34 \\
35 \\
34\end{array}$ & $\begin{array}{l}6.2 \\
6.5 \\
4.8 \\
5.1 \\
8.6 \\
4.9 \\
5.3 \\
5.4 \\
9.6 \\
5.4 \\
7.5 \\
6.7 \\
4.6 \\
7.2 \\
7.7 \\
7.4\end{array}$ & $\begin{array}{l}4.7 \\
6.4 \\
4.7 \\
5.3 \\
8.3 \\
3.8 \\
4.8 \\
3.9 \\
7.8 \\
4.9 \\
5.1 \\
6.2 \\
3.6 \\
6.2 \\
7.2 \\
5.7\end{array}$ & $\begin{array}{r}132 \\
102 \\
102 \\
96 \\
104 \\
129 \\
110 \\
138 \\
123 \\
110 \\
147 \\
108 \\
126 \\
116 \\
108 \\
129\end{array}$ \\
\hline Mean & 33 & 40.0 & $45.3 \dagger$ & 7.39 & 7.35 & 49.4 & 53.7 & 7.35 & 7.32 & 30.9 & 35.6 & 6.4 & $5.5 \dagger$ & 117.5 \\
\hline
\end{tabular}

* Individual $\mathrm{pCO}_{2}$ values are rounded to nearest whole number. Figures for mean $\mathrm{pCO}_{2}$ obtained from unrounded individual values (see Methods).

$\dagger$ Tested by analysis of variance and found significantly different $(p<.01)$ from mean value with air breathing.

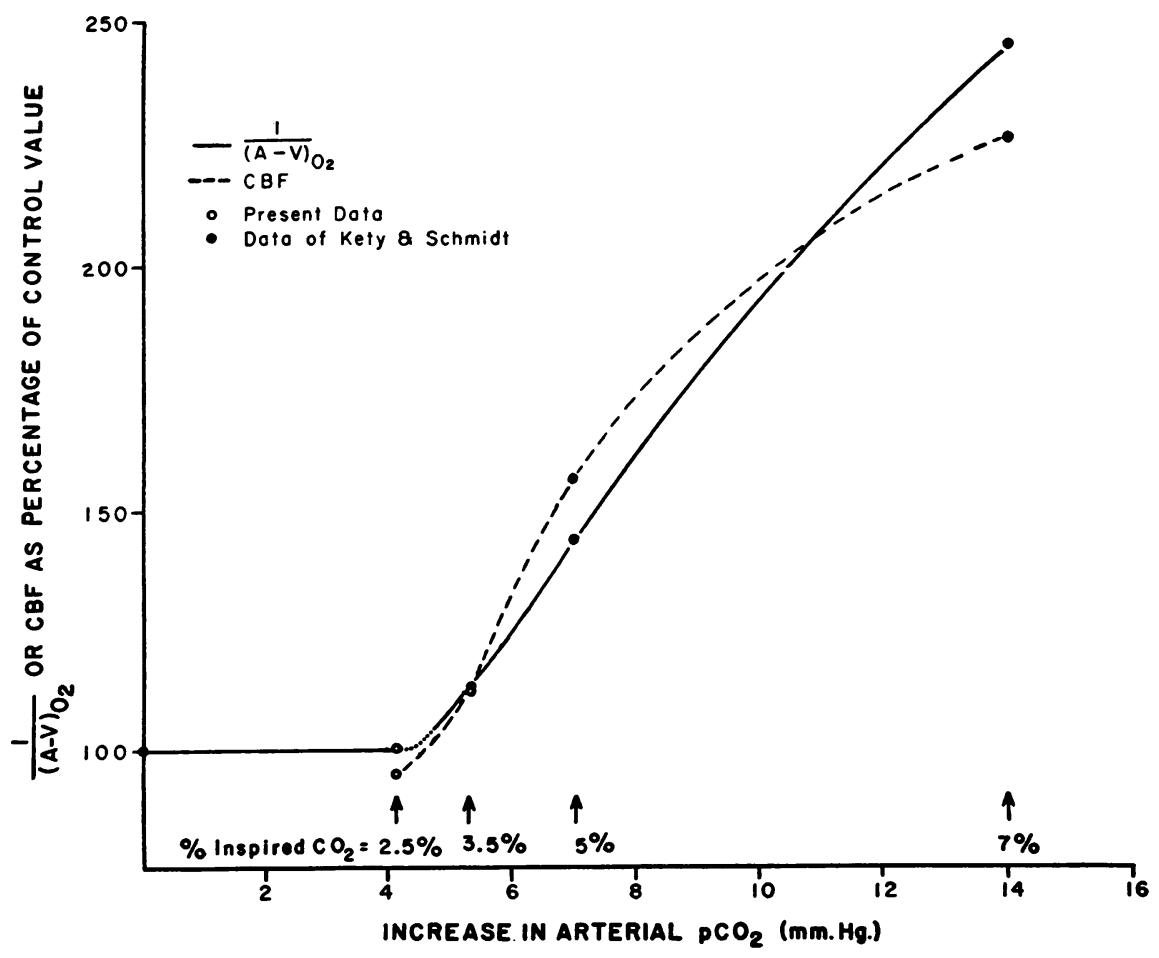

Fig. 1. Relation between the Cerebral Blood flow and Reciprocal of the Cerebral Arteriovenous Oxygen Difference and the Increase in Arterial Carbon Dioxide Tension 
carbon dioxide concentrations, and likewise between the increases in arterial $\mathrm{pCO}_{2}$ produced by these concentrations. The progressive rise in both measures of cerebral blood flow with further increments in the inspired $\mathrm{CO}_{2}$ concentration and the arterial $\mathrm{pCO}_{2}$ is also readily apparent. A 12 to 13 per cent increase in blood flow in these subjects is indicated for a $5.3 \mathrm{~mm}$. rise in $\mathrm{pCO}_{2}$, and a doubling of blood flow is predicted for a 10 to $11 \mathrm{~mm}$. $\mathrm{Hg}$ increase in $\mathrm{CO}_{2}$ tension. In the larger group of 15 subjects, 3.5 per cent $\mathrm{CO}_{2}$ produced a mean increase in $\frac{1}{(\mathrm{~A}-\mathrm{V})_{\mathrm{O}_{2}}}$ of 17 per cent. The mean changes in arterial $\mathrm{pCO}_{2}$ shown in this figure for the $2.5,3.5,5$, and 7 per cent $\mathrm{CO}_{2}$ concentrations are respectively: $4.1,5.3,7.0$, and $14 \mathrm{~mm}$. Hg. A scatter plot of the individual data shows no tendency for the value of $\frac{1}{(\mathrm{~A}-\mathrm{V})_{\mathrm{O}_{2}}}$ to rise with increases in arterial $\mathrm{pCO}_{2}$ smaller than $5 \mathrm{~mm}$. $\mathrm{Hg}$, but a clearly evident tendency for this function to rise with increases of $\mathrm{pCO}_{2}$ of $5 \mathrm{~mm}$. or greater. The same can be said for the individual $C_{B F_{N_{2} O}}$ data, although there are fewer points to indicate the trend of the relationship.

During the inhalation of 3.5 per cent carbon dioxide a definite deepening and slight increase in rate of respiration were usually observed within 10 to 15 minutes. These were associated with slight dyspnea, which in a few subjects became definitely uncomfortable within 30 minutes.

\section{DISCUSSION}

The threshold for cerebral vasodilator effect evidently lies beyond the 2.5 per cent inspired $\mathrm{CO}_{2}$ concentration and its associated mean increase in arterial $\mathrm{CO}_{2}$ tension of $4.1 \mathrm{~mm}$. $\mathrm{Hg}$. This conclusion is based on the absence of changes in the cerebral blood flow, vascular resistance and arteriovenous oxygen difference.

In regard to 3.5 per cent $\mathrm{CO}_{2}$, the validity of the cerebral arteriovenous oxygen difference as a measure of small changes in blood flow, under the conditions of these experiments, should first be considered. Actually, the validity of change in $\frac{1}{(\mathrm{~A}-\mathrm{V})_{\mathrm{O}}}$ as a measure of change in $\mathrm{CBF}$ rests upon the demonstration that cerebral oxygen consumption. as determined by the nitrous oxide method, is not altered by inhalation of carbon dioxide over the concentration range studied. Since $C B F=\frac{C M R_{O_{2}}}{(A-V)_{O_{2}}}$, it is evident that when $\mathrm{CMR}_{\mathrm{O}_{2}}$ is a constant the value of $\frac{1}{(\mathrm{~A}-\mathrm{V})_{\mathrm{O}_{2}}}$ will vary as the blood flow. There seems little reason to doubt the constancy of the $\mathrm{CMR}_{\mathrm{O}_{2}}$, since the number of subjects in the present series combined with those studied by Kety and Schmidt is relatively large. Random errors in the nitrous oxide method would tend to be averaged out, and even systematic errors would not preclude correct conclusions regarding the constancy of cerebral metabolism. It is quite possible that in a limited series of observations, the change in $\frac{1}{(\mathrm{~A}-\mathrm{V})_{\mathrm{O}_{2}}}$ might be the more accurate measure of small changes in blood flow. The nitrous oxide method in any given determination contains more possibilities of error, since it involves multiple analyses, the assumption of equilibrium in respect to nitrous oxide between the brain and jugular venous blood, and other potential sources of error. In the present studies, these two measures of blood flow were for the most part in good agreement, although the larger number of oxygen difference determinations gives this measure somewhat greater statistical validity.

The relations shown in Figure 1 suggest that the cerebrovascular response to increase in arterial $\mathrm{pCO}_{2}$ is a threshold type of phenomenon. The rise from the control level of both the $\mathrm{CBF}_{\mathrm{N}_{2} \mathrm{O}}$ and $\frac{1}{(\mathrm{~A}-\mathrm{V})_{\mathrm{O}_{2}}}$ evidently occurs over a narrow range of increase in arterial $\mathrm{CO}_{2}$ tension. Since mean arterial blood pressure was unaffected by 3.5 per cent $\mathrm{CO}_{2}$ (Table I) and only slightly to moderately affected by 5 per cent and 7 per cent $\mathrm{CO}_{2}$, (5) the rising curve of cerebral blood flow with increase in arterial $\mathrm{CO}_{2}$ tension beyond threshold must have been due primarily to progressive dilatation of cerebral blood vessels.

The mean threshold value for increase in arterial $\mathrm{pCO}_{2}$, below which there was no effect on cerebral vessels and above which there occurred progressive dilation, was approximately $4.5 \mathrm{~mm}$. $\mathrm{Hg}$. It can be seen that both of the curves of Figure 1 when extrapolated downward intersect the control (100 per cent) level very near this point. In the individual data no $\mathrm{pCO}_{2}$ values lie between 
4.2 and $5.0 \mathrm{~mm} . \mathrm{Hg}$, but in each of four subjects who had individual increases of $5.0 \mathrm{~mm}$. $\mathrm{Hg}$ in $\mathrm{pCO}_{2}$ the value of $\frac{1}{(\mathrm{~A}-\mathrm{V})_{\mathrm{O}_{2}}}$ was considerably elevated above control level. This suggests that the $5.0 \mathrm{~mm}$. $\mathrm{Hg}$ increase was beyond threshold. It should be emphasized that the $4.5 \mathrm{~mm}$. $\mathrm{Hg}$ increase in $\mathrm{pCO}_{2}$ represents the average threshold in the subject group studied, and that some individual and group variation would be expected.

It is apparent that inhalation of 3.5 per cent $\mathrm{CO}_{2}$, with its associated mean increase in arterial $\mathrm{pCO}_{2}$ of $5.3 \mathrm{~mm}$. $\mathrm{Hg}$, produced significant cerebral vasodilatation, since the $\mathrm{CBF}_{\mathrm{N}_{2} \mathrm{O}}, \frac{1}{(\mathrm{~A}-\mathrm{V})_{\mathrm{O}_{2}}}$ and the calculated CVR all showed statistically significant changes. Only four of 15 subjects, including the only patient with definite hypertension (C. G.) showed an increase in $\frac{1}{(\mathrm{~A}-\mathrm{V})_{\mathrm{O}_{2}}}$ smaller than eight per cent. The difference between the $\mathrm{pCo}_{2}$ change with 3.5 per cent $\mathrm{CO}_{2}$ and that produced by 2.5 per cent appears surprisingly small in relation to the difference in effect. However, the importance of small changes in $\mathrm{pCO}_{2}$ beyond threshold is emphasized by the increase in blood flow of approximately 50 per cent which is produced by a $7 \mathrm{~mm}$. $\mathrm{Hg}$ increase in $\mathrm{CO}_{2}$ tension (8).

Although the threshold defined above has been stated in terms of change in arterial $\mathrm{pCO}_{2}$, it is possible that it actually represents a threshold for the effects of associated change in hydrogen ion or bicarbonate ion concentration. The work of Schieve and Wilson (15) makes it appear unlikely that the $\mathrm{H}$-ion has any cerebral vasodilator effect, but does not exclude the $\mathrm{HCO}_{3}$-ion. The question must also be raised whether we are dealing with a "pure" $\mathrm{CO}_{2}$ threshold or whether an increase in oxygen tension as a result of hyperventilation might have exerted opposing (vasoconstrictor) effect. However, cerebral vessels are only slightly constricted by 50 per cent oxygen (16) which, on the basis of the alveolar equation (17) and an assumed alveolar-arterial $\mathrm{pO}_{2}$ gradient of $20 \mathrm{~mm}$. $\mathrm{Hg}$, should produce an arterial $\mathrm{pO}_{2}$ of nearly $300 \mathrm{~mm}$. Hg. Since the inspired $\mathrm{pO}_{2}$ itself in these experiments was not over 159 $\mathrm{mm}$. $\mathrm{Hg}$, the possibility appears remote that change in arterial $\mathrm{pO}_{2}$ influenced the results.
The site of action of the carbon dioxide in these experiments was probably the blood vessels themselves. Although an autonomic vasodilator innervation has been demonstrated in the experimental animal (18), its functional significance for man is unknown. It is of interest that recent experiments suggest that a threshold concentration of $\mathrm{CO}_{2}$ is required for respiratory stimulation $(19,20)$. Observations have been made on the effect of an increase in blood $\mathrm{CO}_{2}$ on other vessels of the body deprived of their vasomotor innervation. The vessels in sympathectomized upper extremities in man (21) and the hind limb vessels in dogs, given ganglionic-blocking doses of tetraethylammonium (22), respond alike by vasodilatation to increase in blood carbon dioxide.

The $\mathrm{CO}_{2}$ tension threshold for cerebral vascular effect which is reported in this paper is nonspecific in the sense that it does not indicate which type of vessel was responding: arteries, arterioles, capillaries or venules. Since the increases in venous $\mathrm{pCO}_{2}$ during 2.5 and 3.5 per cent $\mathrm{CO}_{2}$ breathing were only slightly smaller than those in arterial $\mathrm{pCO}_{2}$, the threshold as given would not be greatly in error, regardless of the type of vessel involved. As a corollary we may conclude that, if all of these vessels were responding, the threshold was nearly the same throughout the group. In the case of diseased cerebral blood vessels, or of vessels adapted to chronic abnormality in blood $\mathrm{pCO}_{2}$, it might be anticipated that the thresholds of response to $\mathrm{CO}_{2}$ change would show some differences from those of normal vessels. In cerebral arteriosclerosis the vascular response to 5 per cent $\mathrm{CO}_{2}$ inhalation has been shown to be diminished (23).

In the intrinsic control of the cerebral circulation, it appears probable that carbon dioxide and oxygen tension changes operate simultaneously, and usually in the same direction rather than in competition. Thus, with a fall in cerebral blood flow, the resulting fall in capillary and venous $\mathrm{pO}_{2}$ and rise in $\mathrm{pCO}_{2}$ both represent vasodilator stimuli. The threshold for the combined vascular effects of fall in $\mathrm{pO}_{2}$ and rise in $\mathrm{pCO}_{2}$ quite likely is reached at a smaller value for $\mathrm{pCO}_{2}$ increase than the threshold reported in this paper. From the Fick equation, and the blood nomogram (13) or the physiological $\mathrm{CO}_{2}$ absorption curve (24), it can be shown that, with $\mathrm{CMR}_{\mathrm{O}_{2}}$ constant, cerebral 
blood flow must fall by approximately 30 per cent to raise venous $\mathrm{pCO}_{2}$ to the vasodilator threshold. There is some evidence that vessels actually dilate with a smaller reduction in blood flow (25). Studies on such combined thresholds, and on the threshold of cerebral vascular response to reduction in blood $\mathrm{CO}_{2}$ tension, obviously are needed. The data in the existing literature on the combined effects of arterial $\mathrm{pCO}_{2}$ and $\mathrm{pO}_{2}$ on cerebral blood flow have recently been worked into a useful nomogram by Cannon (26).

Therapeutic applications of our findings remain to be explored. Carbon dioxide in 3.5 per cent concentration appears potentially useful for the treatment of cerebral vascular manifestations produced by inadequate blood flow. Although more weakly vasodilator than 5 per cent $\mathrm{CO}_{2}$, it is considerably more tolerable from the standpoint of dyspnea and can be given for 30 minutes to most patients without producing excessive dyspnea or increases in arterial blood pressures. Its trial in selected patients with cerebral vascular insufficiency seems indicated.

\section{SUMMARY}

1. The vasodilator response of normal cerebral vessels to rapid increase in arterial carbon dioxide tension appears to be a threshold type of phenomenon.

2. In a group of 28 subjects, a mean increase in arterial $\mathrm{CO}_{2}$ tension of less than $4.5 \mathrm{~mm}$. $\mathrm{Hg}$ was without vascular effect, whereas increases greater than this value produced progressive vasodilatation.

3. With constant cerebral metabolism, a reduction in blood flow of approximately 30 per cent would be required to raise end-capillary and venous $\mathrm{pCO}_{2}$ to the vasodilator threshold for this gas.

4. Inhalation of 3.5 per cent carbon dioxide produced a 10 per cent mean increase in cerebral blood flow, but little change in blood pressure in most subjects. It causes considerably less dyspnea than 5 per cent $\mathrm{CO}_{2}$, and may have application in the treatment of states of cerebral vascular insufficiency.

\section{ACKNOWLEDGMENTS}

The technical assistance of the Misses Mary Ruth Fordham, Mary Bell, Mary Upshaw, Mary Herbert,
Sallie Jones, Mrs. Louise Thompson, and Mrs. Marjorie Stephenson is acknowledged with appreciation.

\section{REFERENCES}

1. Bronk, D. W., and Gesell, R., The regulation of respiration. X. Effects of carbon dioxide, sodium bicarbonate, and sodium carbonate on the carotid and femoral flow of blood. Am. J. Physiol., 1927, 82, 170.

2. Schmidt, C. F., The influence of cerebral blood-flow on respiration. I. The respiratory responses to changes in cerebral blood-flow. Am. J. Physiol., 1928, 84, 202.

3. Lennox, W. G., and Gibbs, E. L., The blood flow in the brain and the leg of man, and the changes induced by alteration of blood gases. J. Clin. Invest., 1932, 11, 1155.

4. Kety, S. S., and Schmidt, C. F., The effects of active and passive hyperventilation on cerebral blood flow, cerebral oxygen consumption, cardiac output, and blood pressure of normal young men. J. Clin. Invest., 1946, 25, 107.

5. Kety, S. S., and Schmidt, C. F., The effects of altered arterial tensions of carbon dioxide and oxygen on cerebral blood flow and cerebral oxygen consumption of normal young men. J. Clin. Invest., 1948, 27, 484.

6. Dripps, R. D., and Comroe, J. H. Jr., The respiratory and circulatory response of normal man to inhalation of 7.6 and 10.4 per cent $\mathrm{CO}_{2}$ with a comparison of the maximal ventilation produced by severe muscular exercise, inhalation of $\mathrm{CO}_{2}$ and maximal voluntary hyperventilation. Am. J. Physiol., 1947, 149, 43.

7. Patterson, J. L., Jr., and Heyman, A., Unpublished observations.

8. Kety, S. S., and Schmidt, C. F., The nitrous oxide method for the quantitative determination of cerebral blood flow in man: Theory, procedure and normal values. J. Clin. Invest., 1948, 27, 476.

9. Patterson, J. L., Jr., Heyman, A., and Nichols, F. T., Jr., Cerebral blood flow and oxygen consumption in neurosyphilis. J. Clin. Invest., 1950, 29, 1327.

10. Peters, J. P., and Van Slyke, D. D., Quantitative Clinical Chemistry. Vol. II, Methods. Baltimore, Williams \& Wilkins, 1932.

11. Roughton, F. J. W., Darling, R. C., and Root, W. S., Factors affecting the determination of oxygen capacity, content and pressure in human arterial blood. Am. J. Physiol., 1944, 142, 708.

12. Rosenthal, T. B., The effect of temperature on the $\mathrm{pH}$ of blood and plasma in vitro. J. Biol. Chem., 1948, 173, 25.

13. Singer, R. B., and Hastings, A. B., An improved clinical method for the estimation of disturbances of the acid-base balance of human blood. Medicine, 1948, 27, 223.

14. Handbook of Respiratory Data in Aviation. National Research Council, Committee on Aviation Medi- 
cine, Subcommittee on Oxygen and Anoxia, Washington, D. C., Office of Scientific Research \& Development, 1944.

15. Schieve, J. F., and Wilson, W. P., The changes in cerebral vascular resistance of man in experimental alkalosis and acidosis. J. Clin. Invest., 1953, 32, 33.

16. Heyman, A., Patterson, J. L., Jr., Duke, T. W., and Battey, L. L., The cerebral circulation and metabolism in arteriosclerotic and hypertensive cerebrovascular disease. New England J. Med., 1953, 249, 223.

17. Pappenheimer, J. R., et al., Standardization of definitions and symbols in respiratory physiology. Federation Proc., 1950, 9, 602.

18. Forbes, H. S., Schmidt, C. F., and Nason, G. I., Evidence of vasodilator innervation in the parietal cortex of the cat. Am. J. Physiol., 1939, 125, 216.

19. Nielsen, M., and Smith, H., Studies on the regulation of respiration in acute hypoxia. With an appendix on respiratory control during prolonged hypoxia. Acta physiol. Scandinav., 1951, 24, 293.

20. Hall, F. G., Carbon dioxide and respiratory regulation at altitude. J. Applied Physiol., 1953, 5, 603.

21. Steck, I. E., and Gellhorn, E., The effect of carbon dioxide inhalation on the peripheral blood flow in the normal and in the sympathectomized patient. Am. Heart J., 1939, 18, 206.

22. Patterson, J. L., Jr., Waites, E. J., and McPhaul, M. V., Differential circulatory effects of carbon dioxide. To be published.

23. Novack, P., Shenkin, H. A., Bortin, L., Goluboff, B., and Soffe, A. M., The effects of carbon dioxide inhalation upon the cerebral blood flow and cerebral oxygen consumption in vascular disease. J. Clin. Invest., 1953, 32, 696.

24. Peters, J. P., and Van Slyke, D. D., Quantitative Clinical Chemistry, Vol. I. Interpretations. Baltimore, Williams \& Wilkins, 1931.

25. Scheinberg, P., and Stead, E. A., Jr., The cerebral blood flow in male subjects as measured by the nitrous oxide technique. Normal values for blood flow, oxygen utilization, glucose utilization, and peripheral resistance, with observations on the effect of tilting and anxiety. J. Clin. Invest., 1949, 28, 1163.

26. Cannon, J. L., Estimation of the cerebral blood flow and cerebral oxygen utilization from arterial carbon dioxide tension: I. Development of a method; II. Applications in aviation medicine. U. S. Naval School of Aviation Medicine, Pensacola, 1952, (Project Nos. NM001 059.06.07 and NM001 059.06.08). 